\title{
Bauhaus, Constructivism, Performance
}

\section{Johannes Birringer}

$\mathrm{I}$ the winter of 1929, the Bauhaus arranged one of its famed parties to which guests of the Dessau art school were invited to wear "something metallic." The Metal Party, with its fantastical metallic costumes, and decorations placed throughout the studios, stairways, corridors and open areas, was documented by a few photographs and described by a local newspaper. The tone of the review is full of awe at the inventiveness of the mise en scène. The entire new building in Dessau, which opened its doors in 1925, had been transformed for a temporary festivity inspired by the design vision undergirding the various disciplines taught in the school's curriculum. There are numerous questions that can be raised about the performance vision implied by these large scale parties (e.g. the Kite Festival, the Lantern Festival, the White Party), trying to link it to the Bauhaus dances, Moholy-Nagy's constructivist film/photography, and the theatrical legacy of a radical "design-in motion" concept largely forgotten today. Curiously, Oskar Schlemmer's design-choreography has been mostly treated as a minor historical footnote, while it actually, as I will argue, deserves to be more fully examined in the context of twenty-first century digital art and performance installations.

Since the Bauhaus was predominantly an academy for the visual arts, crafts, and design, the presence of Schlemmer's Stage Workshop seems, at first sight, to have been peripheral, whereas the theatrical parties, from the beginning, found a prominent place in the school's annual calendar. Playful exuberance was encouraged, we learn from the recent exhibition Bauhaus: Art as Life at Barbican Art Gallery, London (May 3-August 12, 2012), which foregrounds such scenes of lively social choreographies. One photograph shows "the building as a stage," with six actors posing on the various floors in masks and costumes, arranged in a vertical/diagonal configuration that renders them almost as architectural elements. More interesting, for the archaeology of site-specific performance, is the transformation of architecture into a stage world, including Schlemmer's musical stairs and the innumerable glass spheres suspended from the ceiling, which inspired some of the artists to photograph themselves against refractive surfaces. Another image shows members of the Stage Workshop in costume on the rooftop, and others depict party-revelers at the Metal Party arriving in outrageous costumes made of aluminum foil, pots and pans, 
spoons, or other functional metallic materials, to slide down a metal chute erected to connect the two Bauhaus buildings.

The catalogue notes that the parties moved from imaginative improvisations to the rhythm of the seasons (Weimar), with the Lantern Festival in the spring and the Kite Festival in the autumn, to spectacular and monumental stage productions (Dessau), where these celebrations promoted contact between the school and the public. The parties were considered important by the master teachers (Johannes Itten lectured on "our play, our party, our work"). Judging from the photographs the festivities gave free rein to masters and students to demonstrate their design creativity, providing opportunities to conceive invitations, posters, costumes, decorations. ${ }^{1}$ There seems to have been a method in these performative festivities, at least

Schlemmer clearly articulates the precise need to "evolve parodies" of all existing theatre forms. This formulation took me by surprise:

The endeavours of the Bauhaus to integrate art and artistic ideals with the craftsmanship and technology by way of investigating the elements of design, and the attempts to direct all activities together toward architecture, naturally exert an influence on the work of the stage. For the stage is after all architectonic: it is ordered and planned, and it provides a setting for form and colour in their liveliest and most versatile form. The stage was there on the very day the Bauhaus opened, because enjoyment in designing was there on that first day. This enjoyment was first expressed in the celebrations (the lantern party and the kite-flying party), in the invention of masks, the making of costumes and the decoration of rooms. And it was expressed in dancing, dancing, dancing! The music evolved from the Bauhaus dance, which developed from the clown dance into the 'Step'; from the concertina to the jazz band. From this 'dance for everyone' evolved the 'dance for the individual' and its reflected form on the stage: the chromatic-normal, the mechanized ballet. From inspiration, whim, and a mind to do something primitive, evolved parodies on existing theatre, opera, drama, circus, and variety shows. Such travesty has positive results: the understanding of the origin of the theatrical play, its conditions and laws. We are breaking conventions where they seem to be already shaky, and we are experimenting with creating new forms. Where can we create such new forms? ${ }^{2}$

This passage has the character of a manifesto, reflecting the extent to which Schlemmer envisioned evolving new versatile physical languages (his plan to stage a dramatic work based on the structure of a building, House of Pi, was not realized) that drew on all available "elements" — media as we would say today — to play with abstract (mathematical), material, and metaphysical dimensions. Seeing him, in a 1926 photograph, perform Musical Clown with Cello, dressed in a colorful skirt and holding an elongated rectangular "cello," one senses this celebratory enjoyment in designing new performance forms through invention of shapes and moving-object mutations. Light-footed, animated, he is the clown that does research into kite-flying-the 
mathematics of dance (Bewegungsmathematik) and the mechanics of joints only a pre-text for the deframing of the figure and the extrusions of the "figural," as Deleuze will call it (in his writing on Francis Bacon who also distended the human body in ways we had barely imagined).

In retrospect, watching archival footage of his pieces and the few recreations that were attempted, we can also see the cinematographic/digital imagination implicit in this work, the freeze-frames and stop-motion images and reverse angles, the montage of movement-images, the transpositions and recombinations of elements, the counterpoint between dancing and not-dancing: his objects always acting as strange rearticulations of motion. I will return to this idea of the "choreographic object."

Founder Walter Gropius's experimental model of education eventually focused on the development of prototypes that might yield commissions, bringing the school closer to its aim of combining artistic inventiveness and industrial production or, as Gropius had formulated the new credo at the 1923 Bauhaus exhibition, to demonstrate the fusion of "Art and Technology." Large-scale technical reproducibility of the objects designed at the Bauhaus was never quite achieved, contrary to the reputation the school was able to build up for its modernist aesthetic. Marcel Breuer's tubular steel chair B3, later named "Wassily," of course became an icon of Bauhaus design, even as Breuer tried hard to get his own patent and secure his artistic authorship of the furniture.

Compared to the Metal or Furniture Workshops, and the other master courses for manual skills in wood, stone, glass, textiles, paint and clay, the Stage Workshop was unlikely to be considered the most pragmatic area for the realization of design products for the Kunstgewerbe (market of goods), which the Bauhaus would later supply with objects reflecting Neue Sachlichkeit, functionality, craftsmanship, and the use of modern materials and construction methods. In 1925, the Bauhaus GmbH company was founded to sell products from the workshops, taking over advertising and marketing. The Bauhaus had already established its own printing press and invented its own typographies. But the stage laboratory gained a particular role in the interlinking of activities, combining art, craftsmanship and play, and since his arrival at the Weimar Bauhaus in 1921, Schlemmer, who first led the Wood and Stone Workshop, then the Sculpture Workshop, took on many of the preparations for the festivals, initially supporting the irreverent student shows that reveled in Dadaesque puppetry, pantomime and satire. Behind the scenes of Bauhaus architecture, Schlemmer assumed important tasks as a kind of multimedia impresario.

Painting, wood, stone, sculpture, performance - this odd combination immediately makes more sense if we recall that Schlemmer was a visual artist. His Triadic Ballet, for which he is mostly remembered, had already been composed between 1916-22 and first premiered in Stuttgart (1922) before being presented during the 1923 Bauhaus exhibition. His work as a painter, sculptor, and designer effectively motivated his experiments as a choreographer and his lasting concern with space and plasticity. The latter, which was akin to the architectonics Gropius imagined for the 
Bauhaus "building" design approaches (interior and exterior design of modern "life processes"), was inscribed into the main activities of the Stage Workshop: the investigation of space, form, color, sound, movement and light. ${ }^{3}$ Schlemmer's paintings, after his early exposure to cubism, reveal a growing interest in the human figure and the mathematics or geometry of the structure of human form. His figure paintings could be considered stage paintings, as already in the 2D works Schlemmer creates during the second decade of the twentieth century he examines the contrast between flattened and voluminous space and the implications of motion-through-space.

A key aspect of the construction of spatial dynamics in Triadic Ballet is the function of the costume. While his later Bauhaus dances have been called "gestural" or "spatial" performances (also involving a strong emphasis on light projection), the Triadic Ballet - in its full version comprising three acts, three performers, twelve dances and eighteen costumes, with each act displaying a different color and mood — displays a predominantly sculptural leitmotif. With exaggerated headdresses and masks, bulbous padded torsos and outfits built with wiring and concentric hoops, extended proplike limbs and conic or spherical appendages, the Triadic "figurines" are constructed to impede movement or shape it in very particular ways, drawing attention to the constructedness of the costumes as well as their materials. The "Abstract One," a figurine from the Black Section, for example, creates an oscillating effect with its black/ white contouring and the different prosthetic-like arms on either side (echoing the triangular, circular or tubular shapes of the sculptural costume). The stylized motion required to move the costume across the stage would impel arhythmic, animated steps, intercut with stillness, or a spinning motion that allows the performer to show off the entire 360 degrees of the shape. It is tempting to think of the Japanese hanamichi or the fashion runway as a parallel to the multi-directionality required here for the movement-display of the costume, a requirement less easily met by the proscenium stage than by more contemporary installation designs allowing audiences to view or engage action from any side. The reference to fashion is by no means facetious, as I think Schlemmer's costumes provided considerable stimulation to de/constructivist designers like Issey Miyake, Rei Kawakubo or Walter van Beirendonck who in their various ways experimented with eccentric combinations of materials and the kind of padded garments that Schlemmer used. Kawakubo, for instance, became well known for her bulbous, padded Dress Meets Body, Body Meets Dress collection of 1996, and designers like Hussein Chalayan and Alexander McQueen have had a penchant for extravagant runway presentations and cross-media scenarios informed by avant-garde installation/performance art.

On the geometric lines, spirals or squares that Schlemmer drew on the floor, the motion might also appear as the movement of chess figures involved in a mysterious abstract game or mathematical series. ${ }^{4}$ We do not see the human body or face of the performer as s/he is completely masked by sculptural form. This aspect of Schlemmer's choreography is particularly interesting as it rejects the expressionism and mimetic theatre conventions of the time, while it also runs counter to all later realist theatre and essentialist — or deconstructive - body art performance traditions of the twentieth century, the latter depending on foregrounding physical corporeality 

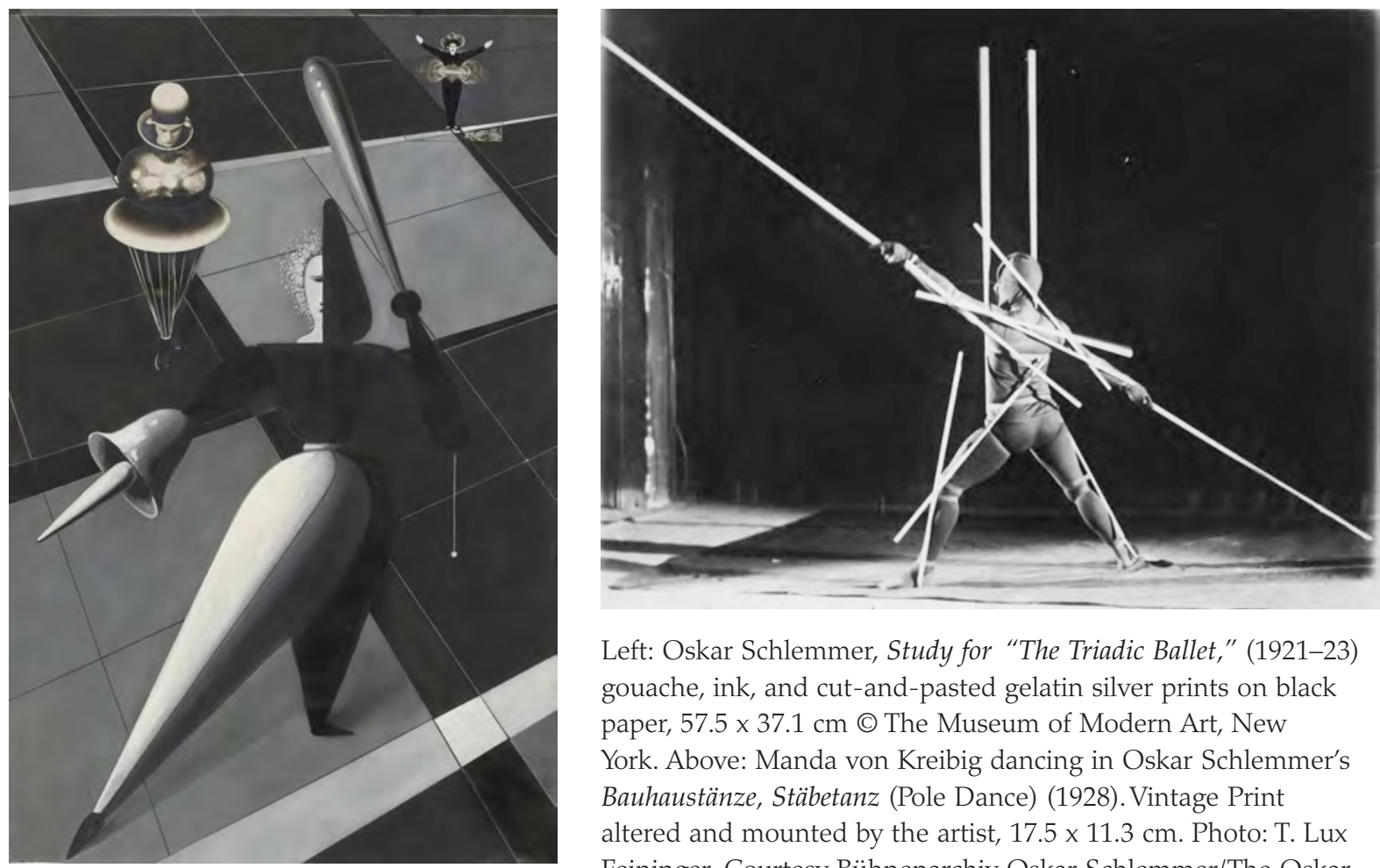

Left: Oskar Schlemmer, Study for "The Triadic Ballet," (1921-23) gouache, ink, and cut-and-pasted gelatin silver prints on black paper, $57.5 \times 37.1 \mathrm{~cm}$ () The Museum of Modern Art, New York. Above: Manda von Kreibig dancing in Oskar Schlemmer's Bauhaustänze, Stäbetanz (Pole Dance) (1928). Vintage Print altered and mounted by the artist, $17.5 \times 11.3 \mathrm{~cm}$. Photo: T. Lux Feininger. Courtesy Bühnenarchiv Oskar Schlemmer/The Oskar Schlemmer Theatre Estate Collection UJS.

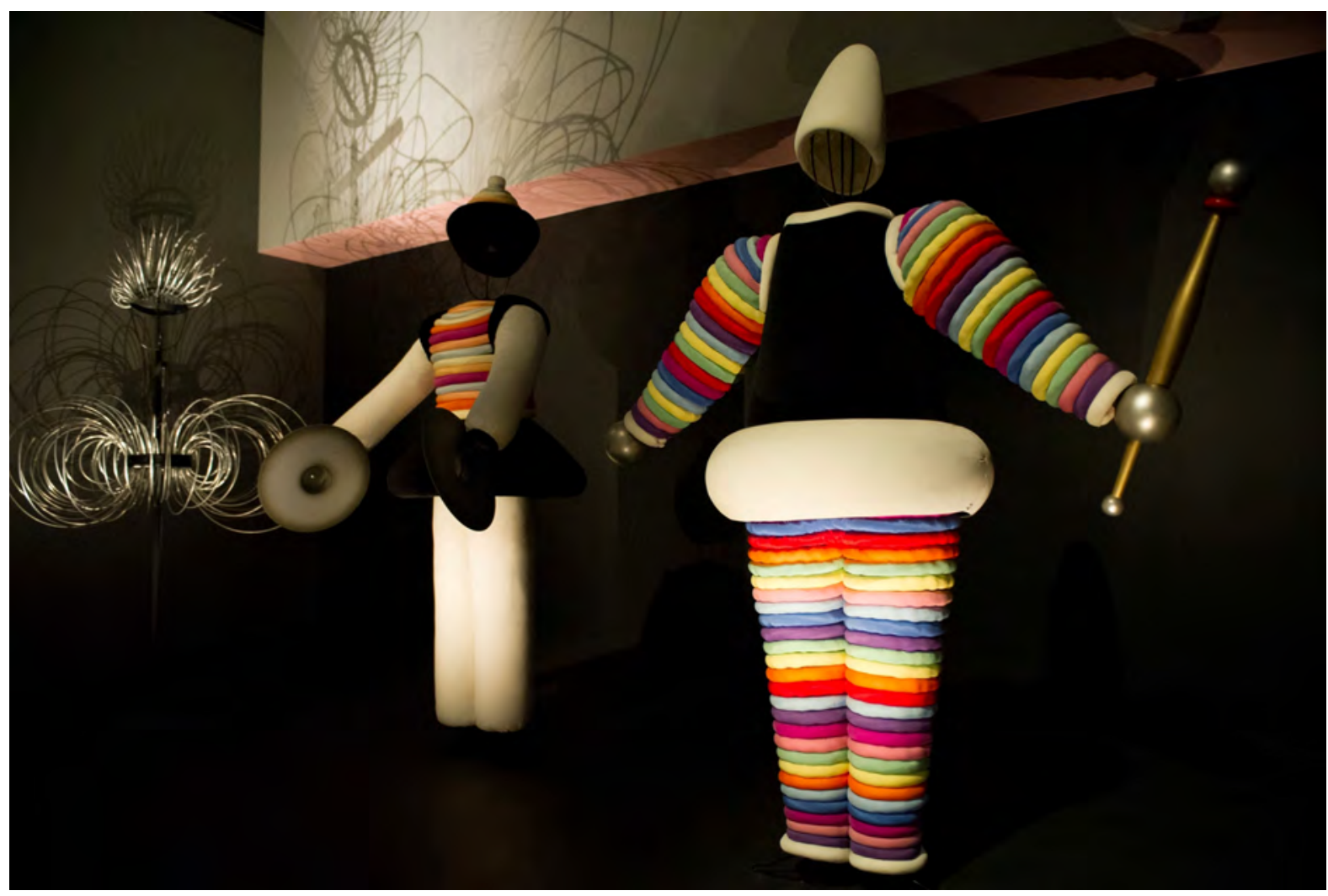

Oskar Schlemmer, Figurinen (recreations) (2012). Photo: Jane Hobson. Courtesy Barbican Art Gallery. 
and social/gender/racial inscriptions of the body. Schlemmer's choreography, without denying bodily materiality, tends to neutralize it insofar as his designs were first drawn and theoretically conceived (on paper), to be applied in motion in order to explore geometric principles and what he considered the "the laws of motion of the human body in space. ${ }^{\prime 5}$ Schlemmer's "mapping" of the figure in space is most beautifully captured in the two drawings of Figur und Raumlineatur and Egozentrische Raumlineatur, both published with his essay on "Mensch und Kunstfigur."

Interestingly, in this mapping he draws the un-costumed human figure inside a cubic stage space or container, Figur und Raumlineatur (Figure and Space Delineation) showing a full stage environment with a static figure downstage center, whereas Egozentrische Raumlineatur (Egocentric Space Delineation) resembles a close-up shot of a figure in motion. Trimingham acutely observes how Schlemmer indicates in "Mathematics of the Dance" that using mathematical principles to measure space necessarily involves treating space as abstract, stable and Euclidian, whereas the body in motion is no longer a simple measurable phenomenon. ${ }^{6}$ The horizontal, vertical and diagonal lines in Figure and Space Delineation position the human figure in the center of an imaginary space volume, and one senses that Schlemmer wants to "delineate" the space perception felt by the performer, the perception of volume and the interconnectedness to the surrounding space. Keeping in mind the multidirectional movement I briefly described in regard to Triadic Ballet, Schlemmer here views the dancer involved in a strictly mathematical and geometrical space, in which precise "mechanical" movements can be performed. But in Egocentric Space Delineation, the dancer moves in the center of attention producing a net of radial motion, perhaps as an effect of more organic movement within a pulsating environment that lacks a depth dimension.

In these diagrams, or biograms, we recognize two approaches that may reflect Schlemmer's view of "man" being a combination of mechanic and organic components, the latter implying an animating force (the concentric lines pointing to the heart or away from it) and a dynamism which point to Schlemmer's continuing interest in Gestalt psychology and a movement-space-making (Gestaltung) approximating the new phenomenology of the "event" (as it was later explored in Merleau-Ponty's philosophy which argues that there can be no space experience without body). Surprisingly Schlemmer even thinks of this becoming-event (he uses the term in a 1927 lecture on "bühne" [stage]) as a quasi-magical relationship with space. In an inverted relationship of the delineations, space also makes body, i.e. spatial organization forecasts and inflects movement. On the philosophical level, then, Schlemmer envisions the figure-body of the dancer to become a temporal Gestalt, transforming space and the abstract theatrical stage through movement into a fluid force field. Melissa Trimingham considers this anthropomorphized space an expression of metaphysics through physical means. The figure curves and modulates space-time, seemingly transporting Kandinsky's dictum of "point and line to plane" into a new, almost anti-gravitational dimension of bodily Gestalten that Kandinsky's system of composition did not allow. Schlemmer's abstraction does not omit the figure but figuralizes spatial organization, a kinaesthetic vision to which William Forsythe's dance 
works and choreographic installations are much indebted. We now credit Forsythe with coining the expression "choreographic object." His objects, for example, The Fact of Matter, White Bouncy Castle, Scattered Crowd, The Defenders and the online research project Synchronous Objects (http://synchronousobjects.osu.edu), transpose dance from the stage into other manifestations - participatory installations, architectural environments, cartographies, soundings, the digital platform with its animated graphic materials, generative data, and algorithms.

Consequently, Kunstfigur is not to be confused with inanimate objects or marionettes: the figural ambiguously combines the living organism with the artificiality of costumed, masked or accessoried plasticity, necessarily redistributing the centers of gravity if the costume's material animates and torques the body in particular ways. The fluidity of space explored in Schlemmer's dance works - and "dance" was a term Schlemmer only used for lack of a better word - requires what we today call embodiment, a real body extended into living spatiality. Yet the costume materials provoke the double (artificial) construction of a kinaesthetic body and animated design. Contemporary architects like Marcos Novak, Greg Lynn or Lars Spuybroek have seized upon this idea of a breathing or liquid architecture, often using timebased animation techniques to inform architectural design, animating form and overcoming ideas of the static, fixed, and inert nature of architecture to transform space and form into highly plastic and mutable entities. With the help of software not available to Schlemmer, they use topological geometries to twist, bend, deform, and differentiate structure, almost bio-morphogenetically, perhaps even to imagine a "performative" architecture. At the 2012 Kinetica Art Fair in London, Greek architect Alexandros Kallegias and the Sharisharishari Studio introduced a tensegrity canopy design model constructed from biometal/artifical muscle material which can flex in response to touch, light and sound, suggesting that built architecture could behave like skin.

Schlemmer's hardware and software tools, so to speak, were his costumes and the accessories he used in the Bauhaustänze, allowing him a range of possibilities to change bodily relationships to the exterior space and, arguably, also to interior "egocentric" experience of the performer who had to wear space, so to speak, and to develop particular haptic sensibilities. Taking the figure and continuing its borders (for example, in Pole Dance or Hoop Dance), Schlemmer wrapped it and folded it into an enlarged context.

Schlemmer's most significant contribution to modern and postmodern theatre/ performance is this insistence on choreographing with costume materials and abstract non-mimetic, non-narrative action. One can also call it a form of non-acting even if the animated Kunstfigur (art figure) - and Kleist's famous essay on the marionette theatre looms behind it - requires a technique similar to the relationship we recognize between puppeteer and puppet. The performer of Schlemmer's Triadic Ballet figurines is the (unseen) puppeteer, the "operator" of the costumes (puppet) or material form. In terms of contemporary digital performance we can describe Schlemmer's constructivist approach as an operational system; the material 
determines the movement, stimulating articulation and emergence, perhaps even inducing involuntary movement (a movement quality much appreciated by Stelarc or Marcel-lí Antúnez Roca when they invite the body to be stimulated via electrical signals), which would not contradict Schlemmer's emphasis on the figure and its precise adaptation to space and internal/external rhythms. Figures, plasticities, light, and sound are construction processes as well as technical organisms, silhouettes of scenic rhythm. The costume materials inform the interactional movement scenarios, with light and sound, but the technical system is also modular and distributed. Thus, Schlemmer is not interested in expressive musical accompaniment but in formal precision of physical/rhythmical tones and percussive noises.

Material movement and material sound — and silence — are spacings, spatializations exactly as noise artists and sound composers of the musique concrète movement would later explore them to a much fuller extent, initiating the extraordinary constellations of sound/phonographic/electronic art in the 20th century recently reviewed in the ZKM exhibition Sound Art: Klang als Medium der Kunst (http://soundart.zkm .de/). Schlemmer knew of recording and amplifying technologies but did not have access to them at the Bauhaus; from his writings we gather that he was imagining the stage as a synesthetic system, with the visual and aural intermeshing as discrete elements, polyrhythmically co-existing. In biological terms, the system behaves like the dynamic of a living organism subject to environmental influence and adapting to it: "The Abstract," "Wire Figure," "Spiral," "Golden Sphere," "Disk Dancer" becoming more complex, variegated, or modulated, especially in their contrapuntal differences, and the dance pieces were of course shown in series, crystallizing different accentuations and colors. "In The Triadic Ballet," Raman Schlemmer writes, "it is the costume that determines movement, conditioning the dancer to new expressions. As much as the static, sculptural costumes and masks inhibit the dancer's range of motion - in a synthesis of body and costume - they introduce, encourage and intensify specific new movements. The costumes become ambulatory architectures." 7

In the early work the operations are mostly performed on the costumes which he had drawn and sketched beforehand, the built-up costumes constricting movement in particular ways, as suggested above. In the Dessau Bauhaustänze - a series of eleven short pieces including Stäbetanz, Metalltanz, Glastanz, Reifentanz, Kulissentanz, etc. - the emphasis shifts to performance with objects/accessories that are operational extensions of bodily architecture and again affect the spatial dynamics of the performed movement as well as the entire environment, as in Metalltanz, with light reflecting off the metal surfaces of set and costume. Here the embodied presence of the operator and the choreographic operations become even more fascinating as radical instances of an abstracting aesthetic that resists representation (and any mimetic associations of "puppet") but reveals, all the same, a complex manipulation of the textural characteristics of the object. Schlemmer's predecessor in the stage workshop, Lothar Schreyer, had favored expressionist theatre performance. But with the arrival of Schlemmer, Moholy-Nagy, and also Kandinsky, the new scenic and light experiments clearly point towards abstraction and a constructivism affected by the revolutionary art created by the Russian avant-garde. ${ }^{8}$ 
Soviet constructivism, if we think of the socialist modernization envisioned by Tatlin, Rodchenko, Popova, Stepanova, Exter, or Vesnin, endeavored to use analysis of the materials and forms (of art) for utilitarian purposes, for the design of functional objects and the organization of a new society. Such a productivism must have chimed to some extent with the rationalist, functionalist ideology prevailing at the Bauhaus (when they were designing objects and not letting the kites fly). After all, the utopian ethos of the Bauhaus architects and monteurs harbored the same monumental vision for the building of a "cathedral of socialism" that Tatlin encapsulated in his Tower. Yet we also recall that Kandinsky's spiritualism was viewed with skepticism by the Russian avant-garde, forcing him to leave Russia, as he was later forced to leave Germany under the Nazi regime that declared his work degenerate. Kandinsky's more playful, malleable and biomorphic shapes, painted in exile in Paris, reverberate with the bioconstructivist tendencies in Schlemmer's Bauhaustänze - and the humorous tone of the latter is perhaps not acknowledged strongly enough. Schlemmer, the Musical Clown with cello, launched his body-figures into space, sound, light. Rhythms can parody design, too. Some of the equilibristics in these object dances remind me of Japanese Kabuki performances, with their attenuated gestures and freeze-frame postures. They play with perception, and they sometimes appear hobbled in a Buster Keaton sense. We can now turn to the peculiar rhythms and montage techniques in Schlemmer's and Moholy-Nagy's work in order to circumscribe the new "art and technology" envisioned here, pointing beyond the "form follows function" design concept associated with the Bauhaus.

Unlike Moholy-Nagy, Schlemmer did not work directly with new media technologies available back then (photography, film, photomontage), but his vision of the future theatre encompasses a wide range of transformative means, and a graphic emphasis on fluid plasticity now often taken for granted on the digital stage or in virtual reality design. The 1923 Bauhaus exhibition featuring Schlemmer's Triadic Ballet, in a program titled Mechanical Cabaret also showing Kurt Schmidt's Mechanical Ballet (a performance of abstract figures with brightly colored cut-outs of geometric forms attached to the dancers' black leotards, moving across the stage like automatons), indicates that Schlemmer himself was less interested in the robotic even though he enjoyed the clownesque humor underlying the mechanics, lighting effects and collapsible flats. The technical problems that occurred during the Cabaret, turning the "art and technology" motto into something of a joke as Trimingham concludes, contributed to Schlemmer's reservations about a mechanical theatre. His respect for Meyerhold's biomechanics and his plans for expanding the Triadic Ballet suggest that he was more concerned with the development of the figural, and with complex choreographic organization of the kind that choreographers of the current digital era have favored when they strap wired exoskeletons on dancers (for motion capture and telematics) or build interface/screen systems that respond to motion in real-time, enabling co-evolutions between bodies, wearable technologies and computational environment, as Yoko Ando recently demonstrated in a performance of Reacting Space for Dividual Behavior at YCAM (Japan). 

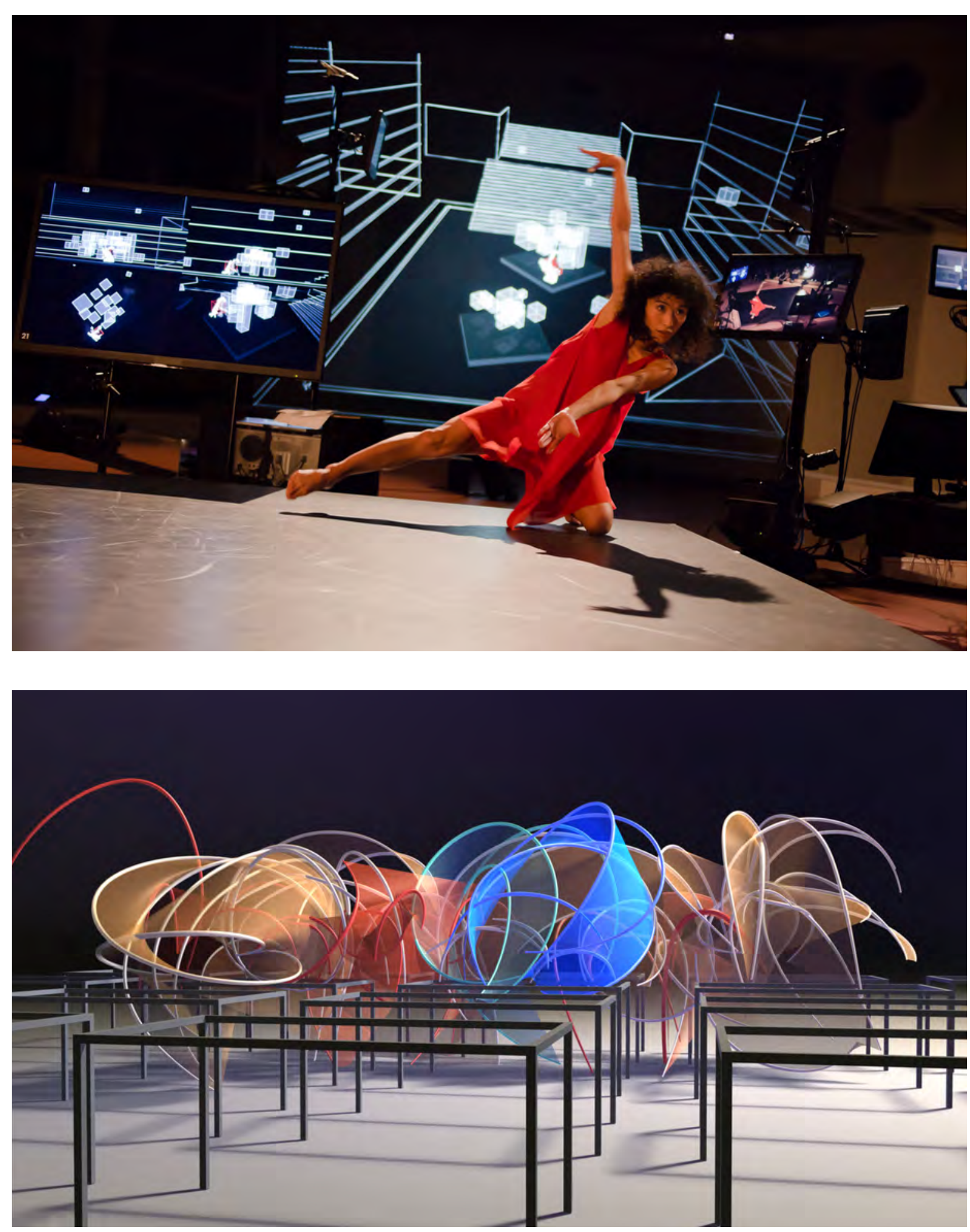

Top: Yoko Ando, Reacting Space for Dividual Behavior (2012) () YCAM. Courtesy YCAM. Bottom: 3D Alignment Forms, animation of dancer's traceforms in One Flat Thing, reproduced mapped to 3D space. Courtesy Synchronous Objects Project, The Ohio State University, and The Forsythe Company. 
Ando's choreography, using the Kinect camera interface to interact with projected virtual geometries, and Forsythe's choreographic installations in which the visitors engage an environment filled with objects, echo Moholy-Nagy's intermedial assemblages and the claim that the application of new techniques, from photomontage and photoplastics to engineering and science, inevitably generates new perceptional relationships. A theatrical collaboration between Moholy-Nagy and Schlemmer would strike us as logical, but the two artists worked side by side, not together. The challenging paradox of Schlemmer's design-in-motion is that he was not only developing the precursor forms of today's wearables - already overcoming the framing function of the screenic or technical image (photograph, cinematic frame) and empowering the body as an articulator of spatial information, and also a new performance technique which, in his writings, he clearly imagines to be a figural poetics of movement. ${ }^{9}$ The performance of the objects and accessories, especially in Stäbetanz, Reifentanz, and Glastanz, but also the use of light projections and shadows in Lichtspiel, implied a careful task-oriented movement style of gestural behavior (completely uncommon at the time, it would later form one of the primary methods in the Judson Church era of postmodern dance, Fluxus and Happenings) which gained its poetic quality through Schlemmer's insistence on the formal power of the total Gestaltung, the complete spatial rhythmicization through plastic structures.

If we look at a sequence of the animated poles in Stäbetanz, we see the mutating shapes, lines, and patterns created by the performing body with its extended limbs, the wearables here generating a mobile visual geometry and tensile relationships that construct new perspectives through pure manipulation, as Moholy-Nagy would call it, pushing far beyond a simple mechanistic/functional approach. The poetic quality of these figurations is also affected by the illumination of the white poles against the dark space. The chiaroscuro line "drawings," with their strong light/dark contrasts and clear architecture, transform pictorial space into 3D cinematic space. One immediately thinks of Moholy-Nagy's film Ein Lichtspiel: schwarz weiss grau (Light Play: black white grey), created in 1930 with the kinetic assemblage/sculpture (Light Space Modulator) built to produce the mesmerizing shadow and light effects.

The Light Space Modulator was a motorized sculpture made of glass, mirror, steel, and acrylic. It became a crucial object for Moholy-Nagy for more than two decades, and after constructing it (1922-30), he displayed it both as a kinetic installation and made the film with it, originally meant to consist of six parts, but only the last part was filmed. The first five parts were supposed to show different forms of light in set combinations: from the self-lighting match, automobile headlights, reflections, moonlight, and colored projections with prisms and mirrors to the refractive production of the "light prop" itself. The surviving silent film segment reveals MoholyNagy's constructivist aesthetic and his interest in Tatlin, Malevich, and Lissitsky, with their visions of aerodromes and radio stations, architecture of mass communication for the new world, as well as his preoccupation with the kinetic "organism of motion" in the city with its skyscrapers, factories, and the developing industrial landscape of the young century. Alongside the new typographies with floating letters which Moholy-Nagy designed for the Bauhaus publications, his photograms and 
photoplastic experiments (multiple photographic re-mixes of his montages) show his fervent embrace of new technologies.

The organism of motion, envisioned as a Light Prop for an Electric Stage, was designed as a kinetic sculpture composed of color, light and movement. Moholy-Nagy here literally imagines light as performance art, the "light play" of a cubic box, containing a glass and polished metal mechanism, placed alone on a darkened stage, with the audience watching how the machine responds to an illumination sequence created by innumerable colored light bulbs flashing on and off. This theatrical vision, developed in tandem with Gropius's plans for a "Total Theatre," must have bemused Schlemmer, but Moholy-Nagy underlined his belief in a technologically oriented future in the groundbreaking Malerei, Photographie, Film (1925), published as part of the Bauhaus books, where he develops his theoretical ideas on photography and film, juxtaposing examples of photograms, photoplastics, photomontage works, double exposures, solarized images, mirror reflections and distortions, aerial and microscopic shots, x-rays, reflected light displays, animated films and advertisements. ${ }^{10}$

Schlemmer's Bauhaustänze reveal a stunning synchronicity with Moholy-Nagy's kinetic dispositif, suggesting that their visions are complementary in the emphasis on coalescence of sensory communication and sculptural gesture. Both artists, in their experiments with motion, light, space, and Faktur (Mohology-Nagy's term for surface aspects, the perceptible effects of the performative treatment of a material), exceed a productivist constructivism concerned with industrial usage and a union of purpose and material. Both artists are pioneers of what is now called hybrid art, in a much expanded context of discourses and historical trajectories. Schlemmer's Hoop Dance is sheer geometric-figural poetry in motion, the circles and suspended spirals perform to clicking and percussive tones while Moholy-Nagy's Light Space Modulator rotates to generate its own subtle tingling, crackling noises, powerfully resonating with the foremost abstract motion projections from Marey to Richter, Eggeling, and Fischinger's space-light-art: audiovisual painting in time. Schlemmer's mise en scène in fact behaves much like Moholy-Nagy's film in 3D, almost as if the dance were an expanded kinematographic study of movement through objects. His Hoop Dance is a mutating and moving world, the suspended figurines slowly turning and twisting between and above the multi-layered hoops.

The spatial, organizational and structural armature of this work has significant conceptual ramifications for contemporary digital performance, dance, and installation art. When I look at the transpositions of William Forsythe's choreography for One Flat Thing, reproduced to the animated recombinations in Synchronous Objects, for example, the Generative Drawing Tool or the 3D Alignment Forms Object, I glimpse many relationships to Schlemmer's furnishing of design-in-motion and Moholy-Nagy's kinetic modulator. Noticeably, One Flat Thing, reproduced is performed on unusual spatial ground: twenty tables form the matrix of choreographic space and the topological grid for some of the "sculptural" data processing and vector graphics in Synchronous Objects (SO). SO presents collaborative research on organizational principles in Forsythe's choreography, conducted at Ohio State 
University's Advanced Computing Center for the Arts and Design, such multidisciplinary centers providing today's versions of a Bauhaus workshop. The researchers analyze and creatively redeploy spatial data from the dance, re-visualizing the kinetic dispositif. SO is also a series of re-mappings (delineations, in Schlemmer's sense) of the distributed flows of the dancers' movements, providing tools that allow the user to trace, re-imagine and re-draw spatio-temporal behaviors from the dance, experiencing on screen the dramaturgies I have tried to address here, the participatory "event-design" now associated with interactive installations but already anticipated in the Bauhaus parties and Schlemmer's spatial mobilizations. Forsythe's artistic and research interest in architectural notions of spatiality, ideas of measure (mathematics, algorithms) and choreography has been amply documented. ${ }^{11}$ Still, it surprises that Forsythe, among other contemporary choreographers, is often linked to the legacy of Laban or Balanchine, and the visual stage aesthetics of Robert Wilson, Robert Lepage, or Romeo Castellucci, rather than to the early twentieth century constructivists. Schlemmer's negligible historical impact can only be explained by the relative insignificance - within interdisciplinary discourses on art, media and performance - attributed to sculpture and costume-design. But only a few jump-cuts are needed in this film on modern motion to realize the critical value of wearable design, and Schlemmer's magical figurines, for repositioning the object of performance in new media culture.

\section{NOTES}

1. See Bauhaus: Art as Life, exhibition catalogue (London: Koenig Books/Barbican Art Gallery, 2012), 27ff.

2. Oskar Schlemmer, "The Stage and the Bauhaus" (1926), in Bauhaus: Art as Life, 196.

3. See Schlemmer in Melissa Trimingham, The Theatre of the Bauhaus (London: Routledge, 2011), 18. Trimingham's thoughtful reconsideration of Schlemmer's significance inspired this essay. She also wrote the chapter on "bauhaus lighthouse" (200-206) for Bauhaus: Art as Life, emphasizing the Gestaltung of space through light, which might put Schlemmer into interesting conceptual relationships with Adolphe Appia's innovations at Hellerau.

4. Nicolas Salazar-Sutil has created interesting experiments with mathematics/dance as artistic director of C8 (The Configur8 Project), exploring symbolic languages (mathematics, computer language) and the use of media and technology in digital performance. In 2010, for example, he participated in "Performing Topology" at Goldsmiths, investigating the use of concepts from the mathematical field of topology, such as transformations, boundaries, fields and continuities as they might be relevant for understanding performance space, embodiment and the sensation of changing space.

5. Oskar Schlemmer, "Mensch und Kunstfigur," in W. Gropius/L. Mohology-Nagy, eds., Die Bühne im Bauhaus (München: Albert Langen, 1925), 17. The initial Bauhaus book was reissued, in translation, as The Theater of the Bauhaus, ed. Walter Gropius/Arthur S. Wensinger (Middletown, CT: Wesleyan University, 1961). Reprinted Baltimore: Johns Hopkins Univ. Press/PAJ Books, 1996.

6. Quoted in Trimingham, The Theatre of the Bauhaus, 89.

7. C. Raman Schlemmer, quoted in Bauhaus: Art as Life, 195. 
8. The repression of German romanticism, the gothic, and expressionism at the Bauhaus is a fascinating subject for another essay; one rarely finds commentary on Bauhaus performance in the context of early modern dance, yet not too far from Weimar, at the Hellerau Festspielhaus, Émile Jaques-Dalcroze had conducted his eurhythmic music/dance and gymnastic workshop productions from which Mary Wigman's Ausdruckstanz emerged. There are subliminal resonances between Schlemmer's spatial action and Meyerhold's biomechanics performed on Liubov Popova's stage machine (a machine-like moving structure with platforms and whirling wheels); similarly, Lissitzky's drawings for an "electro-mechanical" staging of the futurist opera Victory over the Sun (published in the extraordinary 1923 Portfolio of lithographs) offer a constructivist vision contemporaneous with Schlemmer's ideas for a future "dynamic, tectonic, mechanical, automatic and electric stage" ("Man and Art Figure," 19).

9. See "The Mathematics of Dance" and "Man and Art Figure," his main contributions to the 1925 book Die Bühne im Bauhaus/The Theatre of the Bauhaus. Schlemmer thus anticipates Artaud's metaphysics-in-action, the complex poetry of tonalities, resonances, and animated hieroglyphics (Artaud calls them "unperverted pantomime," in reference to the oriental theatre he admired), yet his work is more strongly centered on the transformative power of the three-dimensional plastic form of the costumes or objects.

10. See Bauhaus: Art as Life, 258.

11. For example, Stephen Turk, "Tables of Weights and Measures: Architecture and the Synchronous Objects Project," in Gabriele Klein and Sandra Noeth, eds., Emerging Bodies: The Performance of Worldmaking in Dance and Choreography (Bielefeld: transcript, 2011), 195-206; Erin Manning, "Propositions for the Verge: William Forsythe's Choreographic Objects," Inflexions: A Journal for Research Creation 2 (2009), http://www.inflexions.org/n2_manninghtml.html.

JOHANNES BIRRINGER is a contributing editor to PAJ and director of the Design and Performance Lab at Brunel University, London. The DAP-Lab's latest dance work, for the time being, an homage to the futurist opera Victory over the Sun (1913), premiered in London in 2012. 